\section{Bürgerversicherung als Jobkiller}

Käme nach der Bundestagswahl im nächsten Jahr die von SPD, Bündnis 90/Die Grünen und Die Linke favorisierte Bürgerversicherung, würden zehntausende Jobs in der privaten Krankenversicherung (PKV) wegfallen. Zu diesem Ergebnis kommt eine aktuelle Studie des Berliner IGES Instituts im Auftrag der gewerkschaftsnahen Hans-Böckler-Stiftung. Die Studie befasst sich mit drei verschiedenen Ausstiegsszenarien. Je nach Modell entfielen der Studie zufolge mit der gesetzlichen Krankenkasse für alle zwischen 22.700 bis 51.000 Stellen

\section{Gesundheitsapps}

\section{Europaweite Qualitäts- und Datenschutzstandards kommen}

Die Europäische Union (EU) hat die Regulierung des Marktes für Gesundheitsapps fest im Blick. Aktuell erarbeitet die EUKommission einen europaweiten Verhaltenskodex für die Hersteller dieser Applikationen. Dies berichtete das „Handelsblatt“ und stützt sich dabei auf eine Antwort des Bundesgesundheitsministeriums auf eine Kleine Anfrage der Grünen-Bundestagsfraktion. „Auf europäischer Ebene steht eine Selbstverpflichtung der Hersteller von Gesundheitsapps zur Einhaltung von Datenschutzbestimmungen („Code of Conduct“) kurz vor dem Abschluss, die App-Entwicklern Unterstützung bei der Anwendung der geltenden Bestimmungen bieten wird", zitiert die Zeitung aus der Antwort der Bundesregierung. Zudem kündigte die Regierung an, dass die EU-Kommission bis nächstes Jahr ebenfalls Qualitätskriterien erarbeitet, nach denen Applikationen künftig beurteilt werden.

Einigen Grünen-Politikern im Bund und auf EU-Ebene gehen die Arbeiten an Datenschutz- und Qualitätsstandards nicht weit genug. Für Jan Philipp Albrecht, Mitglied der Grünen im Europäischen Parlament, sei der geplante freiwillige Verhaltenskodex "nicht mehr als eine verbindliche Empfehlung". Stattdessen forderte Albrecht einen rechtlich verbindlichen Katalog und eine Gesetzgebung, die den Umgang mit sensiblen Daten festschreibe. Auch die Grünen-Bundestagsabgeordnete Renate Künast kritisierte die EU-weite freiwillige Verpflichtung der Hersteller als ,inakzeptabel“, weil die Apps auf dem deutschen Gesundheitsmarkt schon seit längerer Zeit massenhaft eingesetzt würden. Sie forderte die Regierung auf, dafür zu sorgen, dass Gesundheitsapps transparent, sicher und qualitativ einwandfrei seien. Zudem müsse die Politik sicherstellen, dass die Verbraucher weiterhin die Hoheit über ihre Daten behielten.

\section{cas}

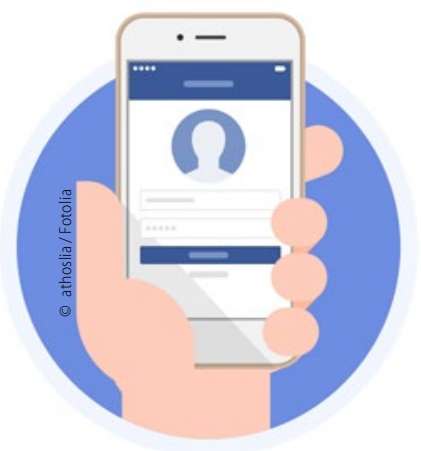

in der PKV. Ausgehend von 68.000 Beschäftigten im PKV-Bereich drohe demnach der Abbau zwischen einem Drittel und rund drei Viertel der Arbeitsplätze. SPD-Gesundheitspolitiker und Verfechter der Bürgerversicherung, Karl Lauterbach, widersprach der Prognose. „Auch die privaten Krankenkassen könnten in unserem Modell die Bürgerversicherung anbieten. Da gingen überhaupt keine Jobs verloren“, erklärte Lauterbach gegenüber der Passauer Neuen Presse.

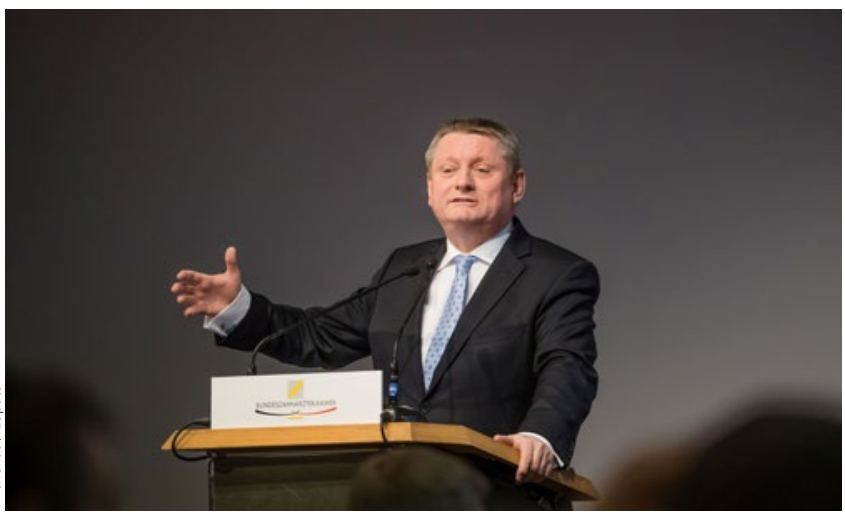

\section{Gesundheitsminister Gröhe beim Zahnärztetag \\ Bekenntnis zu GKV und PKV}

Ein klares Bekenntnis zu Selbstverwaltung und dem Zwei-Säulen-Versicherungsprinzip im Gesundheitswesen hat Bundesgesundheitsminister Hermann Gröhe beim diesjährigen Zahnärztetag abgelegt. Mit einiger Spannung war sein Grußwort von den Delegierten der Zahnärztekammern in Berlin erwartet worden, denn wenige Tage zuvor war im Kabinett der Entwurf des hoch umstrittenen Selbstverwaltungsstärkungsgesetzes verabschiedet worden. Zwar wurden nach Protesten aus den Selbstverwaltungsgremien einige Passagen entschärft, dennoch sorgte das Gesetz beim Zahnärztetag weiter für Gesprächsstoff. „Es ist ja auch mal schön, wenn Protest so kraftvoll ist", sagte Gröhe bemüht launig, um gleich darauf klarzumachen, dass er von der Notwendigkeit und dem Sinn des Gesetzes überzeugt ist. Sorgen in der Selbstverwaltung habe er jedoch mit dem Gesetz nicht auslösen wollen, betonte der Minister. „Wir schreiben mit dem Selbstverwaltungsstärkungsgesetz etwas fest, was Sie schon lange erfolgreich praktizieren“, sagte Gröhe. „Sie haben mit Transparenz gute Erfahrungen gemacht.“

Auch die Sorgen vor einer Bürgerversicherung versuchte der Bundesgesundheitsminister zu zerstreuen. An dem bewährten Zwei-Säulen-Modell von gesetzlicher und privater Krankenversicherung sei nicht zu rütteln, betonte Gröhe. „Es ist ein System, zu dem auch Wettbewerb gehört", sagte er. „Dieses Modell gehört zu unserem starken Fundament des Gesundheitssystems, um das uns viele Länder in der Welt beneiden."

Mehr zum Deutschen Zahnärztetag 2016 ab Seite 26. 